\title{
基于 CDIO 的高等职业教育改革的探索与实践
}

\section{Exploration and Practice of Higher Vocational Education Reform Based on CDIO Model}

\author{
毕丽红 朴立华 张淑敏 \\ Lihong Bi Lihua Piao Shumin Zhang \\ 石家庄铁路职业技术学院 中国·河北 石家庄 050041 \\ Shijiazhuang Institute of Railway Technology, Shijiazhuang, Hebei, 050041, China
}

\begin{abstract}
摘 要: CDIO 工程教育是一种新型模式的国际工程教育合作项目, 是由美国麻省理工学院等发起并推出。与 CDIO 模式 对比，中国现行的高等职业教育模式，还存在着理论占比高，实训、实践占比少的现状，对学生理论能力培养多而对团队 协作能力培养不足、知识学习能力培养多而开拓创新能力培养少等问题，与高等职业人才的培养目标存在差距。在当前高 等职业教育的改革探索中，借鉴 CDIO 人才培养模式，论文提出了 CEC-CDIO 的高等职业教育模式，对中国高等职业教育 的改革与发展有着重要的启发意义。
\end{abstract}

\begin{abstract}
CDIO Engineering Education is a new model of international engineering education cooperation project, which is initiated and launched by MIT. Compared with CDIO mode, the current higher vocational education mode in China still has the problems of high proportion of theory, less proportion of practical training and practice, more theoretical ability training of students and insufficient training of team cooperation ability, more knowledge learning ability and less innovation ability training, which is far from the training goal of higher vocational talents. In the current reform and exploration of higher vocational education, drawing from the CDIO talent training mode, the paper puts forward the CEC-CDIO higher vocational education mode, which has an important enlightenment significance for the reform and development of China's higher vocational education.
\end{abstract}

关键词: CDIO; 高等职业教育; CEC-CDIO

Keywords : CDIO; higher vocational education; CEC-CDIO

DOI : $10.36012 /$ sde.v2i11.2402

\section{CDIO : 国际创新型工程教育模式}

CDIO 是构思 (Conceive)、设计 (Design)、实现 (Implement)、运作 (Operate) 4 个英文单词的缩写，它是“做 中学” 和“基于项目教育和学习” 的集中概括和抽象表达, 以完整工程项目 (包括产品、生产流程和系统) 为系统过程, 从研发到运行的整个生命周期为载体 ${ }^{[1]}$, 如表 1 所示, 让学 生以主动的、实践的、有机联系相关课程的方式学习相关专 业工程。

$\mathrm{CDIO}$ 的理念不仅继承和发展了欧美多年以来的工程 教育改革的理念, 更重要的是它还提出了系统的能力培养。 CDIO 模式易于实施, 它具有全面的实施指南、测试实施过程 和结果检验的 12 条标准, 可操作性较强。CDIO 标准中提出
的工程过程要求是基于行业需求，以及 ABET 的标准 EC2000 制定的，因而能完全满足产业对工程人才质量的要求 ${ }^{[2]}$ 。

\section{CDIO 的教学大纲与标准特点}

\section{1 项目设计与课程体系融为一体}

CDIO 项目与中国工程教育培养计划的不同之处突出表 现在三方面 :一是通过具有导引性的基础课程, 引导学生尽 快入门工程实践项目, 激发学生自主学习兴趣, 让学生尽早 了解工程技术的特点与优势 ;二是相关专业课程以相互有机 融合的方式讲授 ; 三是 CDIO 模式贯穿专业核心课程学习全 过程 , 使学生在学习专业知识的同时亲身体验工程过程 , 使 知识的学习和应用有机结合。

$\mathrm{CDIO}$ 倡导的个人能力、团队协作能力、系统的适应与

【作者简介】毕丽红 (1970 ), 女, 河北石家庄人, 副教授, 从事高等职业教育研究。 
表 1 构思一设计一实施一运作项目工程生命周期过程模型

\begin{tabular}{|c|c|c|c|c|c|c|c|}
\hline \multicolumn{2}{|c|}{ Conception } & \multicolumn{2}{|c|}{ Design } & \multicolumn{2}{|c|}{ Operation } & \multicolumn{2}{|c|}{ Running } \\
\hline $\begin{array}{l}\text { Objectives and } \\
\text { plans }\end{array}$ & $\begin{array}{c}\text { Conceptual } \\
\text { design }\end{array}$ & $\begin{array}{c}\text { Preliminary } \\
\text { design }\end{array}$ & $\begin{array}{l}\text { Construction } \\
\text { design }\end{array}$ & Manufacturing & $\begin{array}{c}\text { System } \\
\text { integration, } \\
\text { testing }\end{array}$ & $\begin{array}{c}\text { Full-cycle } \\
\text { support }\end{array}$ & Evolution \\
\hline $\begin{array}{l}\text { Business } \\
\text { planning }\end{array}$ & $\begin{array}{c}\text { Design } \\
\text { requirements }\end{array}$ & $\begin{array}{l}\text { Requirements } \\
\text { configuration }\end{array}$ & $\begin{array}{l}\text { Component } \\
\text { esign }\end{array}$ & $\begin{array}{c}\text { Hardware } \\
\text { manufacturing }\end{array}$ & $\begin{array}{c}\text { System } \\
\text { integration }\end{array}$ & $\begin{array}{c}\text { Sales Configurati } \\
\text { Running }\end{array}$ & $\begin{array}{c}\text { System } \\
\text { improvements }\end{array}$ \\
\hline Technical & Function & Model & Requirements & assembly & System testing & Logistics & Product family \\
\hline planning & Concept & development & determination & Software design & Improvement & Customer & expansion \\
\hline Customer needs & Technology & System analysis & Failure & Resources & Certificate & feedback & Update \\
\hline Competitors & Structure & System splitting & Prognostic & seeking & acquisition & Maintenance & \\
\hline Project planning & Platform plan & Interface & Analysis & Component & Production & repairs & \\
\hline Business plan & Laws and & determination & Design & testing & Delivery & Recovery & \\
\hline $\begin{array}{c}\text { Market } \\
\text { positioning }\end{array}$ & $\begin{array}{l}\text { regulations } \\
\text { Supply plan }\end{array}$ & Key components & determination & $\begin{array}{c}\text { Component } \\
\text { Improvement }\end{array}$ & & Upgrade & \\
\hline Cost budget & & & & & & & \\
\hline
\end{tabular}

调控能力, 是需要反复培养、逐步提高的, 因此, 各门课程 大纲对 CDIO 能力培养过程有明确的要求并反映在课程考试 考核中。所有的项目的选择设计均要体现团队协作精神，培 养学生在项目推进的过程中提高学习探索能力、增长综合应 用知识能力 提高项目所需要的基本组织能力、管理能力等 ${ }^{[3]}$ 。

\section{2 改革教学管理与评价机制}

CDIO 的学习评价是对学生在个人和社交能力, 在产品、 流程、系统构建和学科知识方面的评价。CDIO 的方法注重 学生综合能力的培养, 能力本位的教学观贯穿课程设计和教 学实践的整个过程。CDIO 模式采用不同的方法评价学生不 同的能力, 以确保评价学生能力过程的有效和合理。这些方 法可能包括卷面笔试、口试、考查、学生反馈、学习笔记、 综合考评、互评、自评、作品展出、报告撰写等。

对学生学习效果的评价, 也要包括行业、企业的考核。 $\mathrm{CDIO}$ 的项目设计与实施来源于相关行业, 对学生工程实践 的能力和产业经验的评价等, 不仅来自教师和学生群体, 也 来自行业标准要求，产业界拥有最大的发言权。项目的总体 价值评判也要根据专业内外的调查数据, 教师、学生、项目 管理者、校友以及利益相关者的数据都是评估的依据。

对学生学习结果的评价可以用来衡量每个学生在学习 目标成果方面达到的程度与效果。评价方法和标准是进行 CDIO 项目教学过程的关键，没有正确的评价手段，无法准 确地判断 CDIO 的教学效果, 而如果采用了不适当的评价 方法和标准来评估，带有很大误差的评估又会反馈到实施
CDIO 的过程中，影响它的正确操作。

\section{3 改革教学方式一探究式学习与实践学习}

改革教学模式，把以“教为主”的教学模式变为以“用 为主” 的教学模式，倡导“学生是中心、教师是引导” 的教 学方式，教师设计教学过程引导学生“主动参与”，在教学 设计项目的驱动下“做中学”“用中学”, 在实训中“练中学”。

在教学过程中教师应提出问题引导学生参与思考与讨 论, 引导学生参与教学与实践过程, 提高学生主动学习的兴 趣，引导学生分析问题、解决问题，以提高学生的分析问 题、解决问题的能力 ; 压缩教师理论授课学时，加大理实一 体的教学比例，即课程采用讲解与实践实训相结合的灵活方 式, 让学生参与授课过程。将所有实训课全部并入相关的课 程内, 教师引导实验内容、统筹安排课程内的实验, 安排设 计与工程实践较为贴切的实验实训内容, 让学生亲自动手和 参与这些实验实训 ${ }^{[4]}$ 。

\section{$2.4 \mathrm{CDIO}$ 与文化教育}

从文化的内涵角度来看, $\mathrm{CDIO}$ 是工程文化教育的特色 模式, 具有先进性的教育理念。从 《CDIO 教学大纲》可以 看到, CDIO 将科学文化与人文文化作为一个整体, 把知识、 思维、方法、规范与精神作为一个整体, 即突出系统的实践 性这一大特点，而成为工程文化教育。思维一一贯穿于大纲 与构思、设计之中, 方法一一贯穿于大纲实施、运行之中， 规范一一直接参考工业界的要求而制订的，即求真务实，精 神——融入大纲，强调“责任感” (职业道德，责任，正直)。 
《CDIO 教学大纲》充分体现了高度重视人文的整体性， 不仅重视科学技术，也重视社会科学。CDIO 教学模式强调 社会价值观、全球价值观，强调企业文化和社会价值观。高 级技术人员不单要有专业的知识基础，还要把人文科学和社 会科学融合进工程技术中。全球 500 强企业, 每个企业都有 其独特的文化宣传内涵，但都是表现其社会价值观和社会责 任感。

因此，《CDIO 教学大纲》不仅把人文体现在内涵上， 而且把科学文化、人文文化也看作一个有机整体, 把与项目 相关的知识、思维、方法、原则、精神也看作一个有机整体。 CDIO 的项目设计实施要重视技术、工程的本身, 特别是要 通过技术、工程本身，通过实践来融合这个有机整体。

\section{3 创新型高等职业教育模式 CEC- CDIO}

石家庄铁路职业技术学院在在高职示范校建设中, 认真 挖掘了《CDIO 教学大纲》的 4 个层面及 12 项标准的内涵, 认真研究了工程技术知识、所需人才的专业能力和素质、团队 协作能力、语言文字沟通能力 , 以及这些能力在企业和社会 的 CDIO 关联体系，在吸收了“ CDIO 模式”的“做中学、产 学合作、国际化”精髓的基础上，创造性地建立了 CEC-CDIO 高等职业教学改革模式。

CEC-CDIO 教育教学模式，注重校企合作，并与构思一 设计一实现一运作进行有机结合。按照校企结合、做中学的 原则, 设置学院重点专业课程体系, 遵循以能力为目标, 以 施工项目为载体，按照高职院校 3 年 6 个学期设计，其中每 个学期 21 周， 7 周为一个学段, 培养期 18 个学段。

依据 CEC-CDIO 课程设置原则, 专业课程设计设置 5 个板块 通识课程板块、自然科学基础板块、技术技能板块、 职业技能板块、拓展技能板块。

“七周学段制” 中各学段板块课程如下: 1 ～ 3 学段 : 在学校完成通识课程板块 ;4 6 学段 :完成自然学科基础 板块、技术技能板块 ;7 9 : 完成职业技能板块 ; $10 \sim 12$ 学段：完成拓展技能板块；13～15 学段 : 完成 $\mathrm{N}$ 个典型工 程任务 $16 \sim 18$ 学段 :顶岗实习。

在 CEC-CDIO教育模式中 采用 WPPF (Work- 基于工作、 Problem- 基于问题、Project Orient- 基于项目导向、Forum-
基于论坛) 教学模式。顶岗实习阶段, 学生可以进入相关校 企合作相关岗位, 由企业工程师和校内专任教师共同指导学 生完成实际工程任务。

随着 CEC-CDIO 的教学改革的逐渐展开, 在各个专业 的人才培养方案、课程设计等教学过程大都在采用 $\mathrm{CEC}-$ CDIO 的理念和方法, 随着 CEC-CDIO 教育模式的推行, 学 生的职业技能、综合能力与素质得到全面提升。

\section{$4 \mathrm{CDIO}$ 模式的思考}

$\mathrm{CDIO}$ 是较为科学的教学模式, 解决了以往教学环节理 论与实践比例不足的问题，提高了学生创新能力的培养环 节, 也带动了学生的学习兴趣，驱动教师不断积累实践教学 经验。同时 ““做中学” “学中做” 的教学模式需要更多的教 学资源保障，在目前大部分高等职业院校中，教学资源不足 是较大的挑战。另外，职业教育模式要走国际化与本土化的 结合的道路，不是国际上所有的东西都可以直接照搬，应不 断创新、发展。CDIO 是一个不断深化的过程, 需要不断地 总结经验。

$\mathrm{CDIO}$ 是一种新型的、开放型教育模式, 不是单一和一 成不变的, 它可以与各个学科、与专业有各种各样的结合模 式，工程教育实践者可以与各个行业、各个学科进行更多的 研究与创新。在高等职业教育教学实践中, 教育者应主动尝 试、积极开拓、吸收与创新、积极探索高等职业教育改革的 新模式，以提高人才培养质量。

\section{参考文献}

[1] John Malmqvist,Kristina Edstr.m,Svante Gunnarsson,etc.The application of CDIO Standards in the evaluation of Swedish engineering degree programmes $[\mathrm{J}]$.World Transaction on Engineering and Technology Education,2006(2):361-364

[2] 杨叔子. 谈谈我对“ CDIO-工程文化教育”的认识 [J]. 中 国大学教学 ,2008(9):6-7.

[3] 查建中. 中国工程教育改革三大战略 [M]. 北京 : 北京理工大学 出版社, 2009 .

[4] 高雪梅, 孙子文, 纪志成.CDIO 方法与我国高等工程教育改革 [J]. 江苏高教 ,2008(5):69-71. 